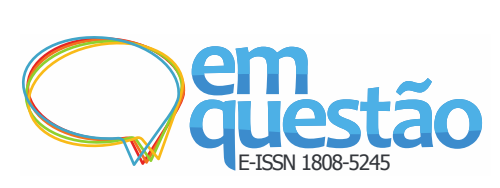

\title{
Os conceitos de apropriação: contribuições à Ciência da Informação
}

\author{
Carmem Lucia Batista \\ Doutora; Universidade de São Paulo, São Paulo, SP, Brasil; \\ carlubatista@gmail.com
}

\begin{abstract}
Resumo: O conceito de apropriação tem sido muito utilizado na Ciência da Informação em relação a diferentes situações: apropriação da informação, de bens culturais, de espaço, de dispositivos tecnológicos, dentre outros. Esse fato nos faz indagar sobre o sentido do conceito nessa área. Por isso, este trabalho tem como objetivo sistematizar referências sobre o conceito de apropriação em diferentes áreas do conhecimento, diferenciando-o de outros, como adaptação, assimilação, interiorização, incorporação e transmissão. A partir dessas referências, são destacados conceitos-chave pertinentes aos usos do conceito em Ciência da Informação. Como método de trabalho, foi feita uma revisão de literatura em diferentes disciplinas em que o conceito é utilizado. Como resultado, são sistematizadas as principais contribuições sobre apropriação que têm relevância e pertinência à Ciência da Informação.
\end{abstract}

Palavras-chave: Apropriação. Conceito. Ciência da Informação.

\section{Introdução}

O conceito de apropriação tem sido muito utilizado na Ciência da Informação em relação a diferentes situações: apropriação da informação, de bens culturais, de espaço, de dispositivos tecnológicos, dentre outros. De certa forma, a raiz do termo (próprio) já nos indica aproximações de significados possíveis, de modo que não nos parece difícil entender o que nos querem dizer quando o conceito é utilizado, mesmo que seja em contextos diferentes.

Na tentativa de melhor compreender o uso desse conceito no contexto da Ciência da Informação, este trabalho tem como objetivo sistematizar referências sobre apropriação.

Como método de trabalho, foi feita uma revisão de literatura em diferentes contextos em que o conceito é utilizado. A busca se deu no Portal de Periódicos da CAPES e no banco de dados da biblioteca da Universidade de 
Paris-Sorbonne. As palavras-chave, apropriação e apropriação cultural, além de serem usadas em português, foram traduzidas em mais três idiomas: inglês (appropriation, cultural appropriation); espanhol (apropiación, apropiación cultural); francês (appropriation, appropriation culturelle). Por essa busca priorizar os sentidos de apropriação em diferentes contextos, não foi feito corte temporal, pois interessava menos o período abrangido do que a discussão do conceito.

Dentre os resultados da busca, os que mais contribuíram com o desenvolvimento dessa pesquisa foram os de produção francesa, como será possível observar mais adiante. Por conseguinte, como resultado desta pesquisa, são sistematizadas as principais contribuições, consideradas as mais pertinentes aos usos do conceito em Ciência da Informação.

\section{Apropriação}

Apropriação é um termo utilizado em várias áreas do conhecimento; em razão disso, seus sentidos extrapolam os significados dados pela etimologia. Conforme o dicionário etimológico, o termo apropriação tem origem latina (appropriationem) e significa “[...] apoderação, apoderamento, posse de alguma cousa, tornar alguma cousa sua, de sua propriedade." (BUENO, 1974, p. 301).

Segmentando o termo, chegamos ao prefixo $a$-, em latim $a d$-, que, como preposição, significa "aproximação, direção para (geralmente com ideia de movimento)" (FARIA, 1956, p. 28). Também há a raiz próprio, em latim proprius, que significa "[...] o que é propriedade de, que pertence a, particular, especial, característico [...]”; e também, “[...] permanente, duradouro, sólido, estável"[...], conforme Faria (1956, p. 781). O termo termina com o sufixo ação, -tionem em latim, um pospositivo que, de acordo com o dicionário Houaiss (HOUAISS; VILLAR; FRANCO, 2001), é formador de substantivos verbais de ação.

Alguns autores tomam como sinônimo de apropriação conceitos como adaptação, assimilação, incorporação, interiorização e transmissão. Assim, na 
busca pela compreensão do sentido de apropriação, os aspectos tangenciais desses conceitos também necessitam ser considerados:

a) adaptação - autores como Kolenc (2008), Serfaty-Garzon (2003) e Mallet (2006) compreendem apropriação como sinônimo de adaptação. Já Leontiev (1978), distingue o termo adaptação de apropriação por acreditar que neste não há a busca de equilíbrio que há naquele. Em termos etimológicos, além do sentido dos prefixo e sufixo já vistos, adaptação tem como raiz o termo latino aptare, que significa “[...] acomodar, ajustar uma coisa a outra [...]", em sentido próprio, e “[...] preparar, equipar, aparelhar, munir [...]", em sentido figurado, conforme Faria (1956, p. 84). Desse modo, o conceito de adaptação implica em ajuste, adequação;

b) assimilação - o dicionário de Bueno (1974, p. 390) apresenta o seguinte significado para assimilação: "Tornar semelhante ou igual. Transformar outras substâncias em sua própria.”. O termo tem origem latina e a raiz da palavra vem de similis, que significa "[...] semelhante, parecido, feito à semelhança [...]” (BUENO, 1974, p. 390). O dicionário filosófico de Lalande (1999) apresenta diversas acepções para o termo assimilação em várias áreas do conhecimento (Filosofia, Pedagogia, Psicologia e outras). Todas as acepções trazem o sentido de um processo, uma transformação, que vai do diferente para o semelhante. Assim, considerando as já mencionadas origens latinas do prefixo e do sufixo, assimilação também implica um movimento de algo diferente que se torna semelhante à outra coisa, passando, também, a ideia de aderência e de aceitação;

c) incorporação - a Enciclopédia de Artes Visuais do Itaú Cultural (2012) considera a apropriação como uma incorporação. Analisando etimologicamente o termo incorporação, temos a preposição in-, que tem como um de seus significados "[...] em, a, sobre; superposição; aproximação; transformação, no interior; valor intensivo, de movimento para dentro, de repouso, de permanência [...]" (HOUAISS; VILLAR; FRANCO, 2001). A raiz do termo é de origem latina (corpus) e significa "[...] qualquer objeto material, substância, matéria, complexo, todo [...]" 


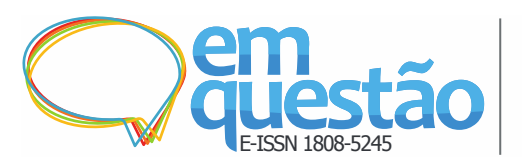

Os conceitos de apropriação: contribuições à Ciência da

(HOUAISS; VILLAR; FRANCO, 2001). Considerando também o sentido do sufixo, é possível concluir que incorporação é uma ação, um movimento de um corpo, uma matéria, para dentro de um outro corpo, no qual permanece em repouso. A diferença entre o sentido etimológico de incorporação e de assimilação é que neste há a ideia de uma descaracterização do objeto assimilado na tentativa de torná-lo semelhante; no caso da incorporação, essa descaracterização não necessariamente ocorre;

d) interiorização - Smolka (2000, p. 28) considera que apropriação e internalização poderiam ser termos utilizados como sinônimos equivalentes porque ambos supõem "[...] algo que o indivíduo toma 'de fora' (de algum lugar) e de alguém (um outro) [...]”, implicando "[...] a ação de um indivíduo sobre algo ao qual ele atribui propriedade particular.”. O prefixo inter-, de origem latina, em sentido próprio, significa “[...] entre, no meio de, no número de, junto de [...]" (FARIA, 1956, p. 495); em latim, interior significa íntimo, recôndito. Dessa forma, podemos entender interiorização como um processo de internalização, situação em que algo exterior é tornado íntimo e interno;

e) transmissão - de acordo com Karol (2004, p. 104), o conceito de transmissão implica sua "[...] articulação de conceitos às noções de parentesco, memória, patrimônio, registro significado." O prefixo trans-, de origem latina, significa "[...] além de, para o outro lado de [...]" (FARIA, 1956, p. 977), e o sufixo remete a ação, movimento. Em latim, transmissum significa "[...] enviar de um lugar para outro." Assim, transmissão é um processo que supõe a passagem de uma ordem das coisas à outra, podendo assumir uma dupla dimensão de deslocamento no movimento implicado.

A semelhança fundamental entre todos esses termos está na ideia de uma ação de deslocamento de uma coisa à outra, movimento em que o objeto deslocado permanece junto ao outro. No caso de adaptação e de assimilação, a ênfase está na transformação do objeto deslocado, num processo de adequação ao novo meio em que é integrado. Em incorporação e interiorização, a ênfase 
está no ambiente de chegada do objeto deslocado: espaço interno de alguma coisa. Já transmissão enfatiza o movimento em si, que até pode ser bilateral.

Saindo da etimologia, alguns dos autores que estudam a apropriação, dentre eles Leontiev (1978) e Vygotsky (2008), partem da concepção desenvolvida por Karl Marx (1818-1883) que, em seus escritos filosóficos de 1844, discorre sobre seu entendimento do processo de apropriação:

O produto do trabalho é o trabalho que tem sido incorporado em um objeto, que se tornou material: é a objetivação do trabalho. A realização do trabalho é a sua objetivação [...] esta realização do trabalho aparece como uma perda de realização para os trabalhadores; a objetivação como perda do objeto e da servidão a ele. (MARX, 1977, p. 68).

[...] assim, quanto mais o trabalhador, por meio de seu trabalho, apropria-se do mundo externo, mais ele se priva dos meios de vida. (MARX, 1977, p. 69).

[...] a apropriação aparece como estranhamento, como alienação; e alienação aparece como apropriação. (MARX, 1977, p. 9, tradução nossa).

Pouco tempo depois, entre 1845 e 1846, Marx e Engels (1979, p. 105), ao tratarem de formas de propriedade e de instrumentos de produção, afirmam que a apropriação das forças produtivas

[...] é o desenvolvimento das capacidades individuais correspondentes aos instrumentos materiais de produção. A apropriação de uma totalidade de instrumentos de produção é, exatamente por isso, o desenvolvimento de uma totalidade de capacidades nos próprios indivíduos.

Sem perder de vista o contexto da Revolução Industrial e da exploração do trabalho operário, o argumento essencial de Marx (1979) são as condições econômicas e políticas do capitalismo, situação em que o sujeito transforma sua força de trabalho em produto e se afasta da possibilidade de acesso a este produto quanto mais trabalho, tempo de vida, dedica a ele; quanto mais o trabalhador se capacita, mais capacidade tem para desenvolver um produto 
elaborado; quanto mais elaborado é o produto, mais caro se torna; tornando também o acesso a ele, pelo trabalhador, mais distante, mais alienado.

Assim, na concepção dos autores, no processo de apropriação, o sujeito não se mantém passivo no contato com o objeto, ele passa por uma transformação que o prepara para relacionar-se nova e ativamente com o objeto, num movimento dialético de desenvolvimento.

A partir dessas concepções, várias derivações de significado do termo foram elaboradas em distintas áreas do conhecimento e com diferentes sentidos.

\subsection{Apropriação como subjetivação}

Na construção das relações sociais, a apropriação está associada ao processo de subjetivação do sujeito. Nessa interação, o sujeito desenvolve uma percepção de si que o permite estruturar o meio social em que vive e ser estruturado por ele, num processo que pode resultar em alienação, em resistência ou em adequação.

A partir da perspectiva de Marx (1977, 1979), Leontiev (1978) desenvolve sua concepção sobre o desenvolvimento socio-histórico do psiquismo humano. Para o autor, a apropriação é condição fundamental ao desenvolvimento do ser social. É por meio do processo de apropriação que o sujeito se torna apto a exprimir sua natureza humana, pois são criadas novas aptidões e funções psíquicas que são produtos do desenvolvimento sociohistórico do homem. Esses produtos têm forma material e objetiva e são resultados de processos de subjetivação de gerações passadas que despertam ou criam a sensibilidade subjetiva humana. Dessa forma, a subjetividade humana é desenvolvida por objetos e por fenômenos que foram produzidos, materializados, como resultado do processo de subjetivação de outras gerações.

Nesse aspecto, a concepção de apropriação de Leontiev (1978) é um processo de transmissão da cultura, que não é adquirida passivamente. $\mathrm{Na}$ descrição de Leontiev (1978, p. 167), esse processo é marcado por uma continuidade que não é dada, ao contrário, é desenvolvida ativamente. Está 
pressuposto um movimento de aprendizagem em relação à realidade física e cultural que propicia o desenvolvimento das capacidades humanas.

Vygotsky (2008) descreve um processo semelhante ao do desenvolvimento das capacidades humanas de Leontiev (1978) que chama de "significação", situação em que o sujeito em interação com o mundo desenvolve uma forma de percepção interior em que passa a um estado mais elevado, que lhe possibilita um novo modo de ver e de manipular as coisas.

Tanto na concepção de Leontiev (1978) quanto na de Vygotsky (2008), na relação com os objetos do mundo, o sujeito fica diante de um problema a resolver; esse problema não é apenas seu, mas de todos. Entretanto a forma de lidar com os objetos do mundo, embora diga respeito a todos, é particular e intransferível, pois a produção de significado que ocorre nessa relação se estabelece a partir do repertório cultural de cada sujeito. Nesse contexto, o "tornar seu" não significa "tomar posse" de alguma coisa, mas adquirir "seu modo próprio" de perceber e de lidar com as coisas do mundo.

Continuando com Leontiev (1978), o excerto abaixo faz referência a mais duas contribuições importantes do autor:

As aquisições do desenvolvimento histórico das aptidões humanas não são simplesmente dadas aos homens nos fenômenos objetivos da cultura material e espiritual que os encarnam, mas são aí apenas postas. Para se apropriar destes resultados, para fazer deles as suas aptidões, "os órgãos da sua individualidade", a criança, o ser humano, deve entrar em relação com os fenômenos do mundo circundante através doutros homens, isto é, num processo de comunicação com eles. Assim, a criança aprende a atividade adequada. Pela sua função, este processo é, portanto, um processo de educação. (LEONTIEV, 1978, p. 272, grifos do autor).

A contribuição mais evidente é a que considera a apropriação como um processo de educação. Para o autor, por meio do desenvolvimento de suas capacidades humanas, possibilitadas pelo trabalho e pelas relações sociais, o sujeito aprende a ser humano, pertencente à espécie, se constrói e se torna apto a viver em sociedade, o que não seria possível se ficasse apenas com o que a natureza lhe dá. A outra contribuição de Leontiev (1978) refere-se à 
comunicação. $\mathrm{O}$ autor considera a comunicação indispensável no processo de apropriação pelos indivíduos dos conhecimentos adquiridos no decurso do desenvolvimento histórico da humanidade, pois para que haja a objetivação da cultura, o homem necessita da intermediação de outros homens - ou seja, necessita de mediação -, entrando em relação com os fenômenos circundantes num processo de comunicação uns com os outros.

No mesmo sentido, Gléonnec (2003) afirma que a apropriação é um processo comunicativo, que se baseia na relação entre o indivíduo e todos aqueles que ajudaram a dar forma, física e simbolicamente, ao objeto apropriado (uma tecnologia, um modo de organização do trabalho etc.). $\mathrm{O}$ autor considera que a apropriação, material ou simbólica, de um objeto é ao mesmo tempo alienação ao sistema que o produziu e a afirmação da identidade e da liberdade individuais. Em outras palavras, o indivíduo estrutura e é estruturado pelo sistema sociocultural do qual participa.

Nesse processo de comunicação, Gléonnec (2003) descreve o que denomina de "cadeia de apropriação". Segundo ele, essa cadeia pode ser decomposta por ciclos que estão encadeados como se formassem vínculos. Cada ciclo corresponde a um espaço-tempo do processo de mudança, que segue o curso das apropriações e das ações que se encadeiam no tempo e no espaço, ciclo após ciclo, num movimento ininterrupto.

Esse processo comunicativo descrito por Gléonnec (2003) é uma síntese, na área da comunicação, dos processos descritos por Leontiev (1978), Vygotsky (2008), Marx (1977) e Marx e Engels (1979).

Chartier (1995) e Ricoeur (1986) contribuem com o desenvolvimento conceitual do termo apropriação ao relacionarem-no à leitura e à interpretação. Chartier (1995) considera o processo de apropriação de textos, de códigos, de modelos compartilhados mais gerador de distinção que as práticas de cada grupo. Para o autor, a apropriação "[...] visa a elaboração de uma história social dos usos e das interpretações, relacionados às suas determinações fundamentais e inscritos nas práticas específicas que os constroem." (CHARTIER, 1995, p. 184). 
A compreensão de Ricoeur (1986) sobre apropriação está relacionada ao processo de interpretação de texto, que, segundo o autor, termina na própria interpretação do sujeito que passa a compreender-se melhor, se compreende de forma diferente, ou até mesmo começa a compreender-se. Para o autor, essa conclusão da inteligência do texto na inteligência de si caracteriza o tipo de filosofia reflexiva chamada "reflexão concreta". O autor destaca, ainda, dois traços do termo apropriação: um que se refere à distância cultural e outro que trata da distância em relação ao sistema de valores sobre o qual o texto se estabelece. Nesse sentido, continua o autor, a interpretação "mais próxima", "equaliza", torna "contemporâneo"e "semelhante", o que é verdadeiramente tornado próprio, o que a princípio era estrangeiro (RICOEUR, 1986, p. 171, grifos do autor).

O processo interpretativo descrito por Ricoeur (1986), que descreve a compreensão do texto como a compreensão de si, está próximo ao conceito de assimilação, não uma assimilação entre sujeito e objeto, mas uma similaridade nos processos de conhecer, que são concomitantes. Outro aspecto relevante é que na concepção do autor, a apropriação é um processo de descolamento simbólico espacial, temporal e cultural com o propósito de tornar próximo. Nesse entendimento, o "tornar seu" tem uma conotação mais afetiva do que possessiva, pois remete à familiaridade. É um sentido próximo ao de interiorização.

Ao estudar a noção de apropriação, Serfaty-Garzon (2003) afirma que o objetivo da possessão do objeto é de torná-lo próprio, ou seja, de adaptá-lo a si e, assim, transformar essa coisa em suporte de expressão de si. A apropriação é, desse modo, ao mesmo tempo uma tomada do objeto e uma dinâmica de ação sobre o mundo material e social com uma intenção de construção do sujeito.

\subsection{Apropriação como ressignificação}

Alguns teóricos das artes plásticas vêm usando a noção de apropriação associada à ressignificação, em razão do deslocamento, tanto físico quanto temporal, sofrido pelo objeto. Isso considerando apenas a relação entre os artistas, ou seja, 
aquele que apropria e o que "sofre" a apropriação. Se nesse processo também considerarmos o público, o espectador, também é necessário acrescentar a alienação como uma característica da apropriação em arte contemporânea, já que a maior parte das pessoas não se dá conta desse jogo de empréstimos entre os artistas. Nesse ponto, em razão da propensão à alienação, o processo de apropriação carrega um traço de semelhança com a apropriação descrita por Marx (1977, 1979).

Quanto aos deslocamentos, a descontextualização espacial do objeto nos remete à ideia de incorporação; já a descontextualização temporal está associada à noção de transmissão. Em ambos os aspectos, o deslocamento desencadeia outros processos de significação, em que o novo ambiente e a nova cultura também atribuem sentido ao objeto.

Perez (2008) e Barbosa (2005) consideram a apropriação um processo semelhante ao de citação e ao de releitura. Segundo Barbosa (2005), na apropriação, as imagens da história da arte são tiradas de seu local de origem e utilizadas para construir uma nova imagem, ou seja, a imagem está contida no trabalho contemporâneo, inteira ou desconstruída. Na citação, conforme a autora, há uma referência indireta a outros artistas e a movimentos estéticos, situação em que podem ser utilizados modos de trabalhar, cor característica de algum artista etc. Para Barbosa (2005, p. 145), tudo isso é releitura, isto é, “[...] olhar o mundo a nosso redor e criar a partir de tantas coisas que vemos no mundo, na arte, na TV... enfim tudo aquilo que nossa retina registra pode ser usado".

Para Perez (2008), o processo descrito por Barbosa (2005) como apropriação é citação, ou citacionismo, um tipo de apropriação. Perez (2008) considera que há dois tipos de apropriação: o primeiro trata de procedimentos em que materiais diversos - que no passado não faziam parte do campo da arte, tais como objetos do cotidiano, conceitos e textos -, são utilizados para criar obras artísticas; o segundo tipo é o citacionismo, que se refere à produção artística que utiliza imagens preexistentes, de outras obras de arte, histórias em quadrinhos, cinema, televisão etc., numa espécie de colagem de fragmentos 
oriundos de fontes diversas. Sobre releitura, Perez (2008) concorda com o significado dado por Barbosa (2005).

Wollheim (2002, p. 187, grifos do autor) considera a apropriação como um empréstimo de uma obra mais antiga e acredita que como resultado "[...] a pintura adquire um conteúdo ou um significado histórico.". De acordo com o autor, o motivo e a imagem emprestados pertencem tanto à obra que apropria quanto à obra da qual foram apropriados, mas o fato de onde o motivo e a imagem vieram somente às vezes pertence à pintura que fez a apropriação, nunca pertence à obra da qual o motivo e a imagem foram apropriados.

Já Perez (2008) discorre sobre a impossibilidade de recuperação do espírito e do sistema de significados em que a obra apropriada foi realizada. Segundo a autora, o criador deve significar as imagens do passado a partir de seu contexto, e as obras devem ser motivadas por questões próprias do tempo vivenciado por ele. Assim, de acordo com a autora, a ideia de apropriação parte do princípio de que "[...] a cultura pertence à humanidade, que (re)constrói seu imaginário a partir de sua herança. Por isso, em vez de negar o passado para afirmar uma suposta originalidade, o artista cria a partir de fragmentos da memória artístico-cultural.” (PEREZ, 2008).

A partir dos autores citados, é possível perceber que em artes plásticas contemporâneas, além do deslocamento, a noção de apropriação está relacionada à questão da autoria e da incorporação.

\subsection{Apropriação como identificação}

No processo de apropriação do espaço, o sujeito ou o grupo estabelece uma relação de identidade e de pertencimento que transforma o ambiente como uma expressão de si. Nessa relação, tanto o sujeito pode pertencer ao espaço quanto o espaço pode, simbolicamente, pertencer ao sujeito. É uma relação de domínio afetivo do espaço, no qual são exercidos controle e posse simbólicos.

Boyer (2010) postula a existência de uma apropriação estética e sensorial e de uma apropriação política do espaço. A apropriação estética e sensorial é 
individual, uma inscrição da corporalidade no espaço, uma reflexão sobre a maneira de habitar os lugares, de senti-los como seu. Ela é o produto dos sentidos e, portanto, uma estética que resulta da relação direta, fenomenológica, entre o indivíduo e a cidade, o bairro, suas formas construídas. Já a apropriação política é coletiva; o imaginário coletivo desempenha plenamente o seu papel na tomada de um território coerente em oposição a um ou mais (oposição de todos os tipos).

Sobre apropriação territorial como construção ou afirmação da identidade e como necessidade de pertencimento, temos os apontamentos de alguns autores.

Ao estudar a apropriação de espaço por movimentos sociais, Ripoll (2004) afirma que há duas grandes formas de apropriação identitária do espaço: a integração de um lugar simbólico já existente (frequentemente já apropriado) na identidade do grupo; ou a produção por esse grupo de um novo lugar simbólico que lhe seja diretamente atribuído.

Sobre a questão, La Soudière (2001, p. 4) observa que a apropriação baseia-se essencialmente no processo de identificação, havendo ou não modificação da realidade em questão. Para o autor, o sujeito se apropria do que gosta de se identificar, do que está disposto a reconhecer como seu. No mesmo sentido, Feildel (2010) afirma que a apropriação será um fenômeno essencialmente cognitivo desde que envolva a capacidade do indivíduo para representar a si mesmo, com os outros, em um espaço, como constituintes desse espaço, dando-lhe um sentido.

Para Audas (2011), o espaço é considerado como suporte e vetor de processos complexos de apropriação e de identificação, dois mecanismos que, para a autora, têm fundamentos diferentes, se alimentam mutuamente e participam da construção de uma relação particular com o espaço, a qual se traduz emocionalmente, marcando a experiência do indivíduo no espaço que ele identifica como sua espacialidade e deixando marcas idealizadas referentes às significações simbólicas. 
Conforme Bonerandi (2005), a apropriação do espaço é considerada como a construção e a delimitação de um "lugar próprio" com o objetivo de tomar consciência de compartilhamento e de provação de um sujeito em relação aos outros; assim, seja no campo da percepção do território, de suas representações ou de sua apropriação simbólica, a construção territorial resulta da cultura.

No que se refere à relação afetiva que desencadeia um sentimento de posse, de propriedade, com o local, também há diversas considerações a respeito.

Audas (2008) compreende a apropriação como um conjunto de ações capazes de dar ao espaço significações por adaptação, transformação ou perturbação. E também pela maneira com que essa apropriação pode fazer emergir uma relação afetiva, positiva ou negativa. No mesmo sentido, Gasnier (2004) define apropriação como um processo psicoespacial, individual ou coletivo, que caracteriza uma relação privilegiada com o lugar e reflete uma forma de liberdade de dispor-se de um espaço, de ter uma pseudopropriedade para usos próprios e de signos culturais específicos.

Também, Fischer (1983) considera que a apropriação se traduz por meio de um tipo de ocupação dada; nessas condições se acha refletida no espaço a estrutura do grupo que se apropria. Assim, continua o autor, a apropriação pode ser definida como o conjunto de práticas exercidas sobre o espaço em resposta às necessidades explícitas de controle ou de personalização e às necessidades implícitas de comunicação ou de reconhecimento.

Ripoll e Veschambre (2005) acreditam que o estágio de aprendizagem em que o indivíduo se familiariza com o lugar é concebido como uma internalização cognitiva: apropriar-se de um espaço significa adquirir conhecimentos teóricos e práticos, saberes e saber-fazer que permitem o moverse sem se perder, mas também o uso de maneira pertinente ou estratégica.

Desse modo, conforme os autores, a apropriação simbólica/identitária de um lugar supõe sua prática concreta, regular e demonstrativa. Por outro lado, mesmo no processo de apropriação para uso exclusivo, o recurso ao simbólico é 
patente, numa busca de legitimação que a força e o direito não são suficientes para garantir. Além do controle, do domínio afetivo do espaço em razão da identificação, em termos geográficos, quando consideramos o território também há a noção de transmissão, de herança cultural.

\subsection{Apropriação como representação simbólica}

No contexto do consumo, a apropriação está associada ao prazer da posse, material ou simbólica, do objeto. Por estar relacionado às emoções e à construção da identidade do possuidor, conforme Brunel, Gallen e Roux (2009), o consumo seria uma forma de "expressão de si" do sujeito. A relação de poder não ocorreria apenas na interação sujeito-objeto, mas também na interação sujeito-sujeito, pois o possuidor/consumidor constrói sua identidade em relação a outros que possuem (relação de identificação, de inclusão) e aos que não possuem (relação de distanciamento, de exclusão). Assim, seriam estabelecidas relações de poder, tanto por "ter" quanto por "ser"; melhor dizendo: acredita-se "ser" alguém por "ter" algo. É um processo de transformação subjetiva que parte da objetividade, da concretude, do objeto, que "empresta" ao sujeito a representação social e simbólica de suas propriedades.

Vários autores discorrem sobre esse tema. Para Cova e Cova (2004), no contexto do consumo, a apropriação se caracteriza pela possessão, que por si só implica um combate na defesa pela preservação dessa posse; ela oferece ao indivíduo o prazer do poder do possuidor e a oportunidade de desfrutar de uma autonomia que se construiria na conduta que ele tem com seu ambiente. De acordo com os autores, atualmente consome-se para existir e não simplesmente para viver, pois, nas chamadas "sociedade de consumo", é por meio do consumo que se construiria e se confirmaria a identidade. Assim, conforme os autores, a experiência do consumo não se reduziria a fazer compras, mas a viver experiências que são incorporadas, pois elas fazem um apelo às emoções do indivíduo.

Na pesquisa de Cova (2003, p. 120), são apresentadas quatro dimensões que formam o conceito de apropriação pelo consumidor: 


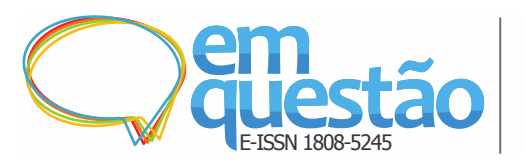

a) a apropriação é considerada unanimamente como a ação de "fazer sua" qualquer coisa;

b) a apropriação supõe uma competência do indivíduo, ou de um grupo de indivíduos, que dá a uma ideia, a um objeto ou a um espaço uma estrutura própria;

c) a apropriação coloca o indivíduo, ou o grupo de indivíduos, livre do prazer da relação com as coisas do mundo;

d) a apropriação de uma ideia, de um objeto ou de um espaço, concede poder ao seu possuidor e, consequentemente, direitos não apenas sobre o objeto ou o espaço, mas também sobre os não possuidores.

Brunel, Gallen e Roux (2009) colaboram com o tema apresentando um tipo de consumo mais específico. Ao estudarem a experiência de consumo alimentar, os autores desenvolvem observações sobre formas de apropriação nesse contexto. Quanto à relação sujeito-objeto, eles apontam duas abordagens: uma primeira abordagem denominada de "lógica descendente" e uma segunda qualificada como "lógica recursiva". A lógica descendente é refletida na dimensão praxiológica de apropriação e é baseada nos trabalhos em psicologia ambiental, segundo os quais a apropriação se manifesta como o exercício de um controle, de um poder físico e/ou mental sobre o objeto. A segunda abordagem trata da apropriação como uma ação recursiva entre sujeito e objeto, isto é, como uma ação dirigida às coisas que, em contrapartida, transformam o sujeito. Dessa forma, o objeto apropriado é definido como um meio de "expressão de si" mesmo.

Segundo Brunel, Gallen e Roux (2009), o fenômeno da ingestão, incorporação, confere um estatuto especial ao consumo de alimentos: ele envolve tanto a apropriação física quanto as propriedades morais e simbólicas dos alimentos. O consumo alimentar é, portanto, uma experiência com uma forte dimensão praxiológica.

No entanto, é sobre a apropriação como uma lógica recursiva de ação recíproca entre o sujeito e o objeto que os autores desenvolvem sua pesquisa. Em razão dos atos que implicam na incorporação de situações de consumo 
alimentar e das potentes cargas simbólicas que os acompanha, os autores partem da abordagem filosófica de Sartre (1999) sobre a interação sujeito-objeto e pelo complemento feito por Belk (1988) à abordagem de Sartre.

Para Sartre (1999), o desejo repousa sobre a ideia de uma incompletude de si que conduz o indivíduo ao que lhe falta: "o objeto do desejo" (objeto material ou não). Essa falta se manifesta como um desejo de fazer ou um desejo de ter. O indivíduo tentará, então, buscar, expressar, confirmar ou negar o sentido de si por meio da possessão da ação. Assim, o desejo exprime a relação do homem com a existência concreta, concebida sobre o modo de apropriação.

Assim, para Brunel, Gallen e Roux (2009), a lógica recursiva da apropriação reside na participação do objeto apropriado na construção do sujeito. De maneira íntima, de acordo com Sartre (1999), o objeto ingerido, incorporado, assimilado, transforma seu possuidor. A partir dessa premissa, Sartre (1999) propõe três métodos:

a) o controle (ou a dominação) de um objeto para o uso pessoal - nenhuma apropriação pode ser mais completa que a apropriação instrumental que permite utilizar a coisa. Aplicado ao consumo de alimentos, conforme Brunel, Gallen e Roux (2009), o controle se inscreve na compra, na ingestão e depois na destruição do produto;

b) a criação - para Sartre (1999), se o indivíduo cria (um quadro, um drama, uma melodia), é por estar na origem de um direito de propriedade sobre o objeto criado que constitui uma parte de si. Sartre (1999) também inclui, como uma forma de criação, a compra e a destruição. Para Brunel, Gallen e Roux (2009), esta é a última forma de dissolução dos objetos, $\boldsymbol{a}$ fortiori, os produtos alimentares para a destruição física acarreta a ingestão;

c) o conhecimento - o desejo de possuir um objeto é também subentendido pelo desejo de conhecê-lo. Para Sartre (1999), isso é apropriação do conhecimento. Um prazer oriundo da apropriação é incluído na própria ideia de descoberta cognitiva. De acordo com Brunel, Gallen e Roux (2009), essa forma de apropriação quando aplicada aos produtos 


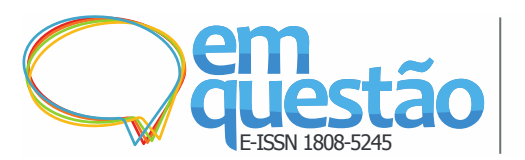

Os conceitos de apropriação: contribuições à Ciência da

alimentares se faz por meio do sistema sensorial e com base em representações mentais que permitem ao indivíduo categorizar e, em seguida, interpretar os estímulos do produto;

d) esses três modos ativos de construção de si mesmo no ato de apropriação foram retomados por Belk (1988), que propôs um quarto, passivo e involuntário: a contaminação - revela a extensão de si por meio de objetos possuídos. Ela é baseada no princípio da incorporação, segundo o qual o homem acredita tornar-se o que come e se manifesta por duas leis: a lei de contágio (ou da contaminação) implica na transferência de modo permanente de propriedades físicas, morais e simbólicas, entre o sujeito e o alimento que estão em contato, mesmo que apenas uma vez; essa lei é complementada pela lei da similaridade, a qual postula que as coisas são o que parecem ser, a imagem e o objeto são apenas um.

Desse modo, no consumo a apropriação tem um sentido de propriedade, de posse que empodera o sujeito, o qual se modifica, constrói sua identidade, por meio do consumo. É uma tomada de poder, de posse, tanto material quanto simbólica que transforma o sujeito.

\subsection{Apropriação como construção de sentido}

No contexto tecnológico, a apropriação de ferramentas é um fato tanto individual quanto social e revela um processo de construção de sentido, resultado de reflexões críticas sobre experiências passadas. Contudo, o aspecto que merece maior atenção nesse processo é a capacidade de transformação recíproca na relação sujeito-objeto, ou seja, a potencialidade de o sujeito se transformar, modificando seu meio e suas relações, com o uso da ferramenta e de transformar a funcionalidade da ferramenta, atribuindo-a diferentes usos, de acordo com sua maneira de perceber e de estar no mundo.

Nesse mesmo sentido, Leontiev (1978) já havia destacado a relação do homem com um instrumento, no qual o sujeito grava modos de ação e operações de trabalho socialmente elaboradas, aproximando-se das operações fixadas no instrumento para desenvolver suas capacidades humanas. 
De Vaujany (2005) considera apropriação como um processo longo que começa bem antes da fase de utilização do objeto e continua muito tempo depois do início da primeira rotina de uso. $\mathrm{O}$ autor faz referência à fase inicial desse processo como "pré-apropriação" - as discussões iniciais e a evocação do objeto, a qual é seguida por uma fase de "apropriação original", em que vários processos sociopolíticos ou psicocognitivos são ativados dentro da organização, com a possibilidade de tensões, subsequentemente facilitado pela introdução de novas rotinas e, finalmente, o processo de extremidades com a criação de um conjunto "definitivo" de rotinas.

No mesmo sentido de De Vaujany (2005) segue Massard (2007, 2009). Esta autora acredita que a apropriação é um fenômeno organizado que evolui ao longo do tempo. Segundo ela, esse processo é individual, pois depende das características de cada participante ou ator, e coletivo porque promove o surgimento de novas estruturas dentro da organização.

De acordo com Fischer (1983), do ponto de vista técnico, a apropriação significa a utilização funcional de um objeto, ela significa uma dominação instrumental: dizemos "eu fiz a ferramenta apropriada para", isto é, o mais próprio, o mais apto.

Já Proulx (2002) destaca a dimensão social da apropriação em tecnologia. O autor questiona se uma "sociedade baseada no conhecimento" deve ser fundada pelo domínio da maioria de seus membros de uma cultura técnica específica - a chamada "cultura digital" - constituída por redes, a necessidade de clareza sobre as condições específicas de uma apropriação individual e coletiva dessa cultura técnica deve tornar-se uma questão primordial para a organização da vida social. A apropriação construtiva da cultura no cotidiano dos usuários e das comunidades aparece, então, como um elemento vital para a inclusão dos indivíduos das comunidades na "sociedade do conhecimento".

Por outro lado, alguns autores consideram que há duas dimensões no processo de apropriação de tecnologias. Para Lemos (2001), a apropriação tem sempre uma dimensão técnica (o treinamento técnico, a destreza na utilização do 
objeto) e outra simbólica (a descarga subjetiva, o imaginário). Assim, de acordo com o autor, a apropriação é ao mesmo tempo uma forma de utilização, de aprendizagem e de domínio técnico, mas também uma forma de desvio em relação às instruções de uso, um espaço completado pelo usuário na lacuna não programada pelo produtor/inventor, ou mesmo pelas finalidades previstas inicialmente pelas instituições.

E também Yahyaoui (2006), que afirma que em termos de apropriação social de tecnologias, a problemática é articulada em torno das significações de uso para a compreensão da apropriação como um processo de criação de sentido, no e para o uso, em toda sua dimensão social. Com essa mesma concepção, Mallet (2006) afirma que a apropriação de uma ferramenta de gestão por um usuário se refere, por um lado, ao processo de adaptação da ferramenta pelo usuário para sua integração no uso quotidiano; por outro lado, ao processo de adaptação do usuário às características da ferramenta e às novas regras veiculadas por ela. Desse modo, trata-se de um processo complexo de construção recíproca do indivíduo e da ferramenta. Nessa perspectiva, de acordo com o autor, a apropriação de ferramentas de gestão se constitui num processo cognitivo, comportamental individual e, também, social.

A partir dessas contribuições, é possível considerar que num processo de apropriação, a relação binária é rompida, cedendo espaço a uma composição triangular (Figura 1). A transformação de binário em triangular faz parte de um processo em que a busca de sínteses resulta num processo dialético, em que o terceiro elemento, a síntese, surge da dicotomia de pares binários:

(1) particular/coletivo; sujeito/mundo; individual/social => integração

(2) sujeito/objeto ou subjetividade/objetividade => interação

(3) material/simbólico => representação

(4) passado/presente => compreensão

(5) próprio/estrangeiro => familiarização

(6) distinto/familiar => domesticação

(7) distância/aproximação => deslocamento 
Essas sínteses compõem um processo que é ao mesmo tempo informativo, comunicativo, educativo, cognitivo, social e cultural: o processo de apropriação, que proporciona ao sujeito a produção de si, a interpretação de si e a expressão de si.

Figura 1 - Dinâmica da apropriação

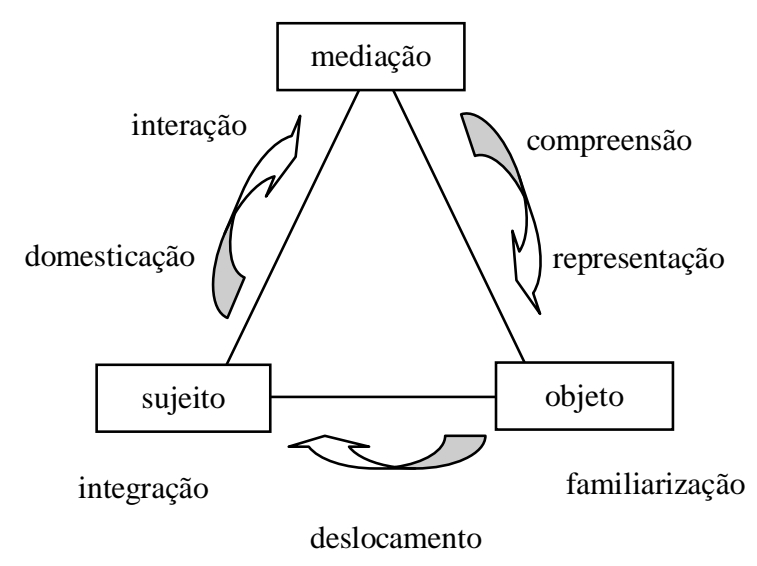

Fonte: Elaborado pela autora.

Nesse sentido, a apropriação é um processo no qual o sujeito "torna seu" um objeto do mundo, ajustando-o, moldando-o a si, atuando afirmativamente nos processos de negociação com os signos, com a cultura. Nesse processo, o objeto, material ou não, sofre um deslocamento espaço-temporal promovido pelo sujeito, que pode alterar ou confirmar o sentido dado pelo seu ambiente de origem, ou seja, pode ressignificar o mundo que lhe chega, a partir de suas percepções, suas expectativas e seus interesses das e pelas atividades. Assim, na apropriação está implicada uma relação dialética, segundo a qual o sujeito, face ao objeto, desenvolve habilidades para construir suas representações do mundo, e por meio dessas construções simbólicas, o objeto adquire significados que expressam e produzem a subjetividade do sujeito. Dizendo de outro modo: ocorre um processo de construção de subjetividade na relação com o objeto e também uma produção de objetos a partir da subjetividade do sujeito. Apropriação seria, assim, "produção", "construção", negociação entre sujeito e objeto, sujeito e mundo. 


\section{Considerações finais}

Cada um dos autores estudados salientou elementos ou aspectos do conceito de apropriação que são pertinentes à Ciência da Informação. A partir desses autores é possível chegar a algumas conclusões.

A relação dialética da apropriação também ocorre entre o meio social e o sujeito, que constrói sua identidade a partir dos objetos disponíveis no mundo e desenvolvidos por gerações passadas, as quais também se apropriaram de objetos deixados por gerações anteriores a elas. Nesse processo, a apropriação vincula o sujeito à transmissão cultural.

Assim, o sujeito, ao estabelecer uma relação dinâmica com o mundo, com a intenção de construir-se e de construí-lo, não faz isso porque "tornou seu" um objeto, material ou simbolicamente, mas porque, na relação com o objeto, ele, o sujeito, toma uma decisão, e a partir disso percebe o mundo com outras perspectivas. Essa relação é dinâmica, inconstante e mutável porque se refere à construção de um ser que sempre se transforma e que está inserido num mundo sempre em mudança. Dessa forma, o processo de apropriação é bem distinto dos de adaptação, assimilação, incorporação, interiorização e transmissão. Dentre as várias diferenças entre esses conceitos, podemos destacar o dinamismo e a produção de si implicados no processo de apropriação em detrimento a: a adequação do processo de adaptação, o conformismo e à aceitação do processo de assimilação; o movimento e o repouso em outro corpo, conforme o processo de incorporação; a internalização do processo de interiorização; a passagem de uma ordem à outra, no processo de transmissão.

Em suma, esses conceitos se referem à mera recepção, transferência, nivelação, homogeneidade, apagamento de diferenças e relação passiva com o mundo físico e simbólico. Já a apropriação visa construção, negociação de representações, tem o propósito de conjugar realidades e interesses distintos. Assim, a apropriação é um processo dialético que envolve a construção e a expressão de si e do mundo, por meio de ações e interlocuções ativas e afirmativas das partes. 


\section{Financiamento}

Este trabalho é adaptação de parte do referencial teórico da pesquisa de doutorado sanduíche, desenvolvida no Brasil e na França, com bolsa da Coordenação de Aperfeiçoamento de Pessoal do Ensino Superior (CAPES).

\section{Referências}

AUDAS, N. De l'espace fonctionnel à l'espace vécu: les modes d'appropriation affective d'un archetype du non-lieu, la gare. In: COLLOQUE ESPACES DE VIE, ESPACES-ENJEUX: ENTRE INVESTISSEMENTS ORDINAIRES ET MOBILISATIONS POLITIQUES, 2008, Rennes. [Actes]. Rennes, 2008.

AUDAS, N. La dynamique affective envers les lieux urbains: la place des temporalités individuelles et urbaines. 2011. Thèse (Doctorat en Urbanisme) École Doctoralle Sciences de l'Homme et de la Societé, Université FrançoisRabelais de Tours, Tours, 2011.

BARBOSA, A. A. T. B. Releitura, citação, apropriação ou o quê? In: BARBOSA, A. M. (Org.). Arte/educação contemporânea: consonâncias internacionais. São Paulo: Cortez, 2005. p. 143-149.

BELK, R. W. Possessions and the extended self. Journal of Consumer Research, Chicago, v. 15, n. 2, p. 139-168, Sep. 1988.

BONERANDI, E. Le recours au patrimoine, modèle culturel pour le territoire? Géocarrefour, Lyon, v. 80, n. 2, 2005.

BOYER, J. Sur l'appropriation collective de l'espace: imaginaire et esthétique de la ville et d'un quartier Lyonnais: Perrache / Sainte-Blandine / Confluence. Lyon: [s.n.], 2010.

BRUNEL, O.; GALLEN, C.; ROUX, D. Le rôle de l'appropriation dans l'expérience de consummation alimentaire: une analyse de blogs. Nantes: Institute d'Economie et de Management de Nantes, 2009.

BUENO, F. S. Grande dicionário etimológico-prosódico da língua portuguesa. Santos: Ed. Brasília, 1974. v. 1.

CHARTIER, R. "Cultura popular": revisando um conceito historiográfico. Estudos Históricos, Rio de Janeiro, v. 8, n. 16, p. 179-192, 1995.

COVA, B. Pourquoi parler de tribus qui consomment? Sociétés, consommation et consommateurs, marketing et sciences sociales à la rencontre de la 
consommation. In: JOURNÉES NORMANDES DE RECHERCHE SUR LA CONSOMMATION, 1., 2003. Actes... [S.1.: s.n.], 2003. p. 69-81.

COVA, B.; COVA, V. L'experience de consommation: de la manipulation à la compromission? In: COLLOQUE “SOCIÉTÉ ET CONSOMMATION”, 2004, Rouen. [Actes]. [S.1.: s.n.], 2004.

DE VAUJANY, F. X. De la pertinence d'une réflexion sur le management de l'appropriation des objets et outils de gestion. In: DE VAUJANY, F. X.. De la conception à l'usage: vers un management de l'appropriation des outils de gestion. Paris : Management e Société, 2005.

FARIA, E. (Org.). Dicionário escolar latino-português. 2. ed. Rio de Janeiro: Ministério da Educação e Cultura, 1956.

FEILDEL, B. Espaces et projets à l'épreuve des affects: pour une reconnaissance du rapport affectif à l'espace dans les pratiques d'aménagement et d'urbanisme. 2010. Thèse (Doctorat en Améngement de l'Espace et Urbanisme) - Université François Rabelais, Tours, 2010.

FISCHER, G. N. Le travail et son espace: de l'appropriation à l'aménagement. Paris: Dunod, 1983.

GASNIER, A. Requalification, ré-appropriation et urbanité. Espaces et sociétés, Paris, n. 21, p.35-39, mars 2004.

GLÉONNEC, M. Communication et changement organisationnel: le concept de chaîne d'appropriation. In: COLLOQUE BILATÉRAL FRANCO-ROUMAIN, 10., 2003, Bucarest. [Actes]. Bucarest, 2003.

HOUAISS, A.; VILLAR, M. S.; FRANCO, F. M. M. Dicionário Houaiss da língua portuguesa. Rio de Janeiro: Objetiva, 2001. CD-ROM.

ITAÚ CULTURAL. Enciclopédia de artes visuais. São Paulo, 2012.

KAROL, M. La transmission: entre l'oubli et le souvenir, le passé et l'avenir. Le Télémaque, Caen, v. 2, n. 26, p. 103-110, 2004.

KOLENC, C. Appropriation de l'espace et expérience de consommation : le cas des rassemblements de joueurs en réseau. In: JOURNÉES DE RECHERCHE DE MARKETING DE BOURGOGNE, 13., 2008, Dijon. [Actes]. Dijon, 2008.

LA SOUDIÈRE, M. De l'esprit de clocher à l'esprit de terroir. Ruralia, Lyon, n. 8, 2001.

LALANDE, A. Vocabulário técnico e crítico da Filosofia. São Paulo: Martins Fontes, 1999. 
LEMOS, A. Apropriação, desvio e despesa na cibercultura. Famecos, Porto Alegre, v. 8, n. 15, p. 44-56, ago. 2001.

LEONTIEV, A. Desenvolvimento do psiquismo. Lisboa: Livros Horizonte, 1978.

MALLET, C. Innovation et mesure de l'appropriation des outils de gestion: proposition d'une démarche de construction d'un tableau de bord. In: COLLOQUE “EN ROUTE VERS LISBONNE”, 2006, Luxembourg. [Actes]. Luxembourg, 2006.

MARX, K. Economic and philosophic manuscripts of 1844. Moscow: Progress Publishers, 1977.

MARX, K; ENGELS, F. A ideologia alemã: Feuerbach. 2. ed. São Paulo: Ciências Humanas, 1979.

MASSARD, N. Le processus d'appropriation d'un progiciel de gestion intégré par l'utilisateur final: vers une compréhension des facteurs d'influence menant aux bonnes pratiques attendues. Aix-Marseille: Université de La Méditerranée, 2007.

MASSARD, N. Revisiter la notion d'appropriation: pour une application au cas des ERP. In: COLLOQUE AIM, 14., 2009, Marrakesh. [Actes]. Marrakesh, 2009.

PEREZ, K. G. Apontamentos sobre o conceito de apropriação e seus desdobramentos na arte contemporânea. Revista Digital Art\&, São Paulo, v. 6, n. 10 , nov. 2008.

PROULX, S. Trajectoires d'usages des technologies de communication: les formes d'appropriation d'une culture numérique comme enjeu d'une société du savoir. Annales des Télécommunications, Paris, v. 57, n. 3-4, p. 180-189, 2002.

RICOEUR, P. Du texte à l'action. Paris: Éditions du Seuil, 1986. (Essais d'Herméneutique, v. 2).

RIPOLL, F. L'appropriation de l'espace au regard des mouvements sociaux contemporains: quelques réflexions sur les enjeux, modalités et ressources de l'action. Espaces et sociétés, Paris, n. 21, p. 45-50, mars 2004.

RIPOLL, F.; VESCHAMBRE, V. Introduction: l'appropriation de l'espace comme problématique. Norois, Rennes, n. 195, 2005.

SARTRE, J.-P. O ser e o nada: ensaio de ontologia fenomenológica. Petrópolis: Vozes, 1999. 
SERFATY-GARZON, P. Dictionnaire critique de l'habitation et du logement. Paris: Armand Colin, 2003. p. 27-30.

SMOLKA, A. L. B. O (im)próprio e o (im)pertinente na apropriação das práticas sociais. Cadernos Cedes, Campinas, v. 20, n. 50, p. 26-40, abr. 2000.

VYGOTSKY, L. S. Pensamento e linguagem. 4. ed. São Paulo: Martins Fontes, 2008.

WOLLHEIM, R. A pintura como arte.São Paulo: Cosac \& Naify, 2002.

YAHYAOUI, Y. Innovation et processus d'appropriation sociale de la technologie. In: COLLOQUE INTERNATIONAL "POLITIQUES PUBLIQUES ET INNOVATION SOCIALE DANS LES PAYS DU MAGHREB”, 2006, Rabat. [Actes]. Rabat, 2006.

\title{
Concepts of appropriation: contributions to Information Science
}

\begin{abstract}
The concept of appropriation has been widely used in Information Science in different contexts: appropriation of information, of cultural heritage, of space, technological dispositive and others. This fact raises the question about the meaning of the concept in this area. Therefore, this work aims to systematize references to the concept of appropriation in different areas of knowledge, differentiating it from other one such as adaptation, assimilation, internalization, incorporation and transmission. From these references, relevant key concepts were highlighted for the use of the concept in Information Science. As a working method, a review of literature in different contexts in which the concept is used was taken. Consequently, the main contributions on the concept of appropriation that has relevance and pertinence to the Information Science were systematized.
\end{abstract}

Keywords: Appropriation. Concept. Information Science.

Recebido: 21/06/2017

Aceito: 03/10/2017 